\title{
Rotura bronquial por una sonda nasoenteral
}

\author{
Bronchial rupture as a complication of nasoenteral tube
}

\author{
Marcelo Felipe Parra-Novoa ${ }^{1}$, Sebastián Sapiain-González ${ }^{1}$, \\ Ana Díaz-Fabres ${ }^{2}$ y Francisco Palacios-García ${ }^{3}$
}

Paciente de 42 años, sin antecedentes. Hospitalizado por neumonía grave SARS-CoV-2 con requerimiento de VMI y TEP asociado; $24 \mathrm{~h}$ posterior a la instalación y uso de una sonda nasoyeyunal evolucionó con deterioro clínico y aumento de parámetros inflamatorios, La radiografía de tórax (Figura 1A), evidenció la sonda en vía aérea, retirándose inmediatamente. Evoluciona con un neumotórax hipertensivo (Figura 1B). Se instaló pleurostomía, sin embargo, persiste con fuga aérea de hasta $50 \%$ del volumen corriente, imposibilitando la ventilación. Se realizó una toracotomía posterolateral, como hallazgos destacan un pulmón hepatizado friable, empiema por nutrición enteral, rotura del bronquio lobar inferior y lesión transfixiante del lóbulo medio, realizándose bilobectomía (media e inferior). Evolución favorable, extubación a las 72 h, posteriormente dado de alta y con seguimiento sin secuelas a 90 días (Figura 1C).

Se debe reforzar la importancia del uso de imágenes como apoyo a la realización de procedimientos invasivos. La pandemia ha planteado distintos desa- fíos, entre ellos se encuentra la alta carga asistencial, el aumento de los pacientes graves con requerimientos de apoyo ventilatorio, nutricional y de accesos vasculares.

Esto necesariamente se traduce en un alto número de procedimientos invasivos y de las complicaciones asociadas. Durante estos meses hemos visto lesiones traqueales por intubación, neumotórax secundarios a accesos vasculares, sondas nutricionales mal posicionadas como la presentada en este caso. También se debe considerar que mayoritariamente los pacientes con COVID-19 se manejan con anticoagulación, lo que contribuye al aumento de complicaciones.

La instalación de sondas enterales debe tener un control imagenológico antes de su uso. Algunos autores reportan la utilidad del uso de la capnografía durante la instalación de las sondas para disminuir este problema, esto parece útil en pacientes ventilados, pero no es aplicable en pacientes no ventilados, por lo que la radiografía de tórax parece ser la medida más costo-efectiva como control posinstalación, conducta masificada en otros procedimientos.
'Servicio de Cirugía. Servicio de Medicina Interna. ${ }^{3}$ Unidad de Paciente Crítico Hospital de Urgencia Asistencia Pública - Facultad de Medicina de la Universidad Finis Terrae. Santiago, Chile.

Recibido 2020-10-01 y aceptado 2020-11-09

\section{Correspondencia a:}

Dr. Marcelo Felipe Parra-Novoa mfparra@gmail.com

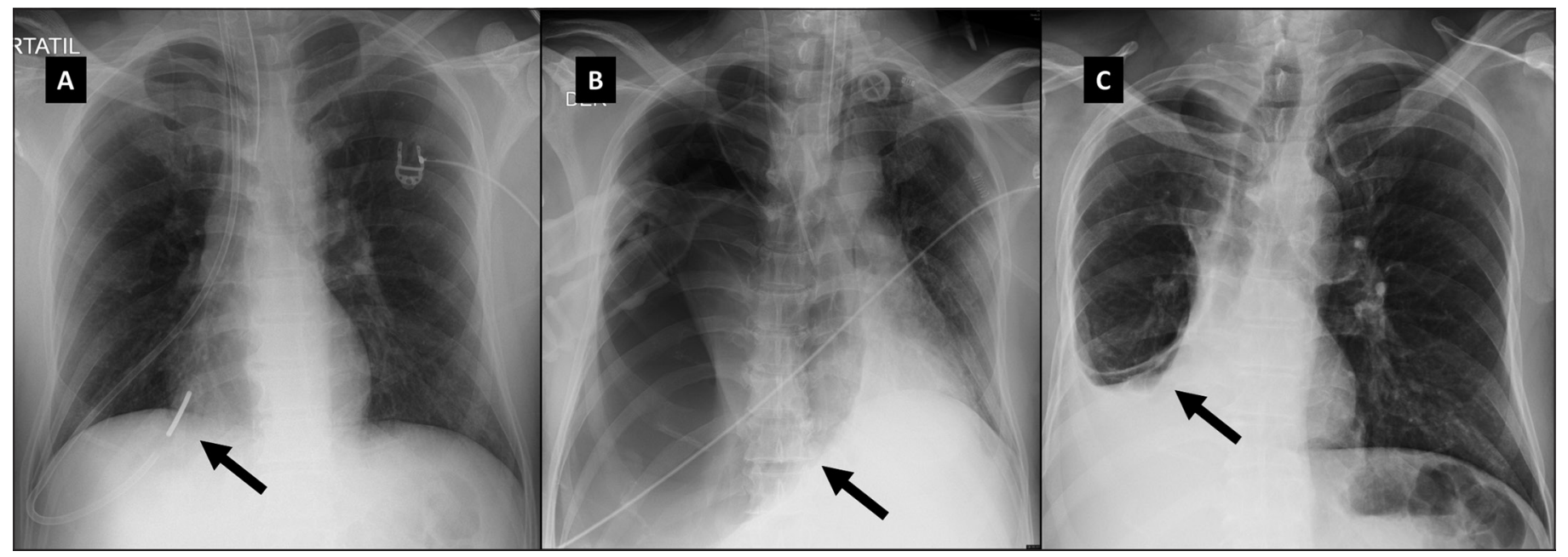

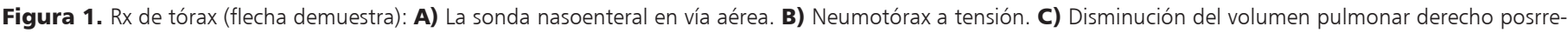
sección sin complicación. 


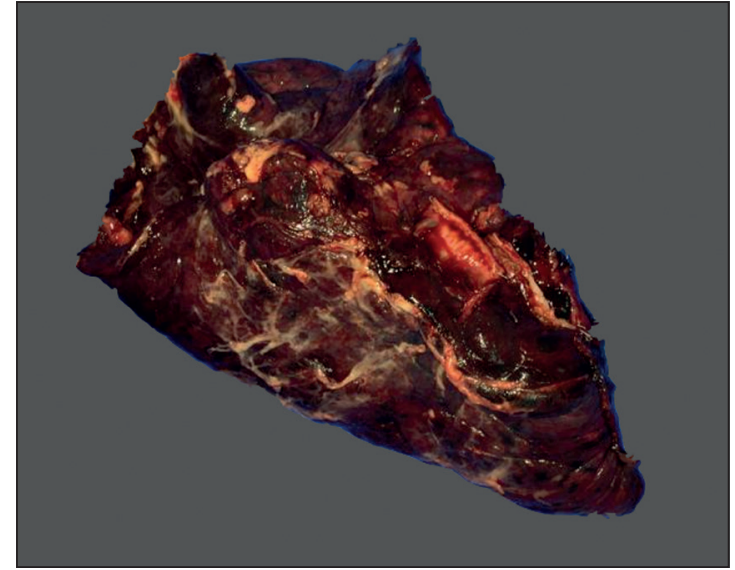

Figura 2. Espécimen quirúrgico: Lóbulo pulmonar inferior derecho con fibrina por empiema asociado.
No existe literatura de resecciones pulmonares en pacientes con COVID-19 en ventilación mecánica. En este caso en particular, dada la friabilidad del tejido pulmonar, se prefirió la lobectomía sobre la resección segmentaria.

\section{Responsabilidades éticas}

Protección de personas y animales. Los autores declaran que para esta investigación no se han realizado experimentos en seres humanos ni en animales.

Confidencialidad de los datos. Los autores declaran que en este artículo no aparecen datos de pacientes.

Conflictos de interés: no hay.

\section{Bibliografía}

1. Stanislaw P. Stawicki, Lena D.

Bronchial nasoenteric tube misplacement: Effective prevention, prompt recognition, and patient safety considerations. Int J Crit Illn Inj Sci. 2016; 6:156-60.

2. Ryu JA, Choi K, Yang JH, Lee DS, Suh GY, Jeon K, et al.
Clinical usefulness of capnographic monitoring when inserting a feeding tube in critically ill patients: retrospective cohort study. BMC Anesthesiol. 2016;16:122. 